\title{
Suggestion for understanding and activation of the nursing home dentist system
}

\author{
Jung-Min Kwag ${ }^{1}$, Inn-Im Park², and Mee-Kyoung Son ${ }^{3,4 *}$ \\ ${ }^{1}$ SK Chemicals Dental Clinic, Seongnam 13494, Republic of Korea \\ ${ }^{2}$ Goodface Dental Clinic, Seoul 06212, Republic of Korea \\ ${ }^{3}$ Department of Prosthodontics, School of Dentistry, Chosun University, Gwangju 61452, Republic of Korea \\ ${ }^{4}$ Oral Biology Research Institute, Chosun University, Gwangju 61452, Republic of Korea
}

(Received Aug 18, 2017; Accepted Sep 25, 2017)

\begin{abstract}
Various medical policies for elderly patients have been introduced in the era of aging. Recent implementation of nursing home dentist systems is a positive opportunity to recognize the significance of oral health care in managing general healthcare and improving the quality of life for elderly people. In addition, it is necessary to strengthen dentists' competencies and key roles in recovering oral function and rehabilitation with changes in the customer-oriented dental care paradigm. This study suggests the path towards stabilizing and activating nursing home dentist systems by understanding the background and current status of nursing home dentist systems, and identifying ways of improving the systems.
\end{abstract}

KEY WORDS: Era of aging, Nursing home dentist, Oral function, Oral rehabilitation

\section{서 론}

최근 노인 인구의 증가에 따른 고령화 문제가 다양한 분 야에서 화두가 되고 있다. 특히 우리나라는 전 세계에서 유래를 찾아보기 힘들 정도의 빠른 속도로 고령화가 진행 되고 있으며, 2026년에는 만 65세 이상의 노인 인구가 총 인구의 $20 \%$ 이상인 초고령 사회에 진입할 것으로 예상된 다[1,2](Table 1).

이와 같은 급속한 고령화는 경제 및 사회 전반에 대한 변화와 더불어 보건복지 분야에서의 새로운 정책의 도입 과 이를 기반으로 한 의료시스템의 변화 필요성을 가속화 시키고 있다. 고령자를 대상으로 한 보건복지정책의 발전 을 살펴보면, 우리나라는 2007년 노인장기요양보험법을 제정하고, 2008년부터 노인장기요양보험 제도를 실시하였 다. 노인 장기요양보험 시행에 맞춰 보건복지부는 2008년 7월부터 치매, 중풍 등 노인성 질환을 가진 노인요양시설

*Corresponding author: Mee-Kyoung Son

Department of Prosthodontics, School of Dentistry, Chosun University, 309 Pilmun-daero, Dong-gu, Gwangju 61452, Republic of Korea Tel.: +82-62-220-3820, Fax: +82-62-227-7811

E-mail: son0513@chosun.ac.kr
입소자들에 대한 서비스 강화를 위해 촉탁의(「노인복지 법」시행규칙 제 22 조를 근거로 함) 제도를 도입함으로써 노인요양시설 내에서 처방전을 발급할 수 있게 되었다[3]. 2009년 7월 1일부터는 노인요양시설에서의 진찰, 처방, 응 급시 이송대책 등 의료적 측면을 강화하기 위한 협약 의 료기관 제도를 도입하였다.

이와 같이 노인 인구를 대상으로 하는 다양한 의료복지 정책이 제정되고 시행되었지만, 노인장기요양보험에 적용 되는 노인 환자들에게 구강보건서비스를 제공하기 위한 제도적 장치는 미비했다. 삶의 질과 관련하여 구강건강관 리의 중요성이 지속적으로 제기되면서 2016년에야 비로소 장기요양시설에 입소한 노인의 건강을 관리하는 촉탁의가 의사, 한의사에서 치과의사로 확대된 '치과촉탁의 제도'가 개정되었다.

그러나 치과촉탁의 제도가 새롭게 개정되었음에도 불구 하고, 2017년 현재 촉탁의로 활동하는 치과의사는 17 개 기관에서 15 명(서울 3 명, 대구 1 명, 경기 7 명, 충남 1 명, 경 북 3명)으로 매우 적다[4]. 이는 치과촉탁의 제도가 노인 환자 및 요양기관 관계자들에게 충분히 홍보되지 못한 점 과 더불어 치과계 내부에서조차도 이에 대한 교육과 인식 이 아직 부족하기 때문으로 판단된다.

이에, 본 논문에서는 먼저 우리나라의 장기요양보험 수 
Jung-Min Kwag et al.

Table 1. Population aging in leading countries

\begin{tabular}{lcccccc}
\hline \multirow{3}{*}{ Division } & \multicolumn{3}{c}{ Target Year } & & \multicolumn{2}{c}{ Necessary Period (year) } \\
\cline { 2 - 3 } & $\begin{array}{c}\text { Aging Society } \\
(7 \%)\end{array}$ & $\begin{array}{c}\text { Aged Society } \\
(14 \%)\end{array}$ & $\begin{array}{c}\text { Superaged Society } \\
(20 \%)\end{array}$ & & $\begin{array}{c}\text { Aged Society } \\
\text { Enrollment }\end{array}$ & $\begin{array}{c}\text { Superaged Society } \\
\text { Enrollment }\end{array}$ \\
\hline Korea & 2000 & 2018 & 2026 & 18 & 8 \\
Japan & 1970 & 1994 & 2006 & 24 & 12 \\
Germany & 1932 & 1972 & 2009 & 40 & 37 \\
the USA & 1948 & 2015 & 2036 & 73 & 21 \\
France & 1864 & 1979 & 2018 & 115 & 39 \\
\hline
\end{tabular}

Data from Ministry of Health and Welfare (2009).

급 현황을 살펴보고, 우리나라보다 앞서 인구의 고령화를 겪고 이를 대비하기 위해 개호보험을 도입하여 구강보건 서비스를 활발히 제공하고 있는 일본의 사례를 통해 치과 촉탁의 제도를 안착시키고 활성화하기 위한 방안을 제시 하고자 한다.

\section{재료 및 방법}

\section{1. 우리나라의 장기요양보험 수급 현황}

2015년 조사 결과, 우리나라 인구의 기대수명은 남자는 79.0세, 여자는 85.2세[5]이지만(Fig. 1) 건강수명은 73세로 약 9년의 차이를 보인다[6]. 이와 같은 기대수명과 건강수 명의 차이는 점점 더 커지는 양상을 보이고 있으며 이는 요양을 필요로 하거나 요양시설에 거주하는 기간이 점점

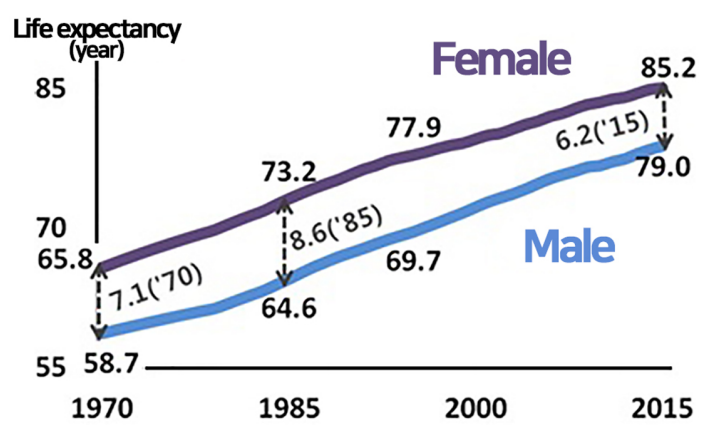

Fig. 1. Life expectancy reported by National Statistical Office (NSO) in 2015.
길어지고 있음을 의미한다.

노인 실태조사에 따르면, 65 세 이상 노인은 평균 2.5 개 의 만성질환을 가지고 있고[7], 장기적으로 요양이 필요한 노인들은 만성질환과 더불어 기능장애도 동반하고 있어 요양 필요와 진료 필요가 동시에 발생하고 있다. 현재, 장 기요양서비스를 제공받기 위해서는 공단에 장기요양등급 신청서를 제출하고, 등급 판정을 받게 되며, 1 등급에서 3 등급의 장기요양등급이나 치매특별등급(5등급)을 받으면 재가급여나 요양시설 서비스를 이용할 수 있다.

국민건강보험공단의 '2016 노인장기요양보험 통계연보' 에 따르면, 2016년 65세 이상 노인은 694만 명으로 2012 년 대비 $17.2 \%$ 증가하였고, 장기요양보험 신청자는 $31.9 \%$ 증가한 84 만 9천 명, 인정자는 $52.1 \%$ 증가한 52만 명으로 나타났다(Fig. 2, Table 2).

장기요양보험 인정자 52 만 명의 각 등급별 인원 현황은 Table 3과 같다. 이처럼 장기요양 보험 인정자가 증가 추

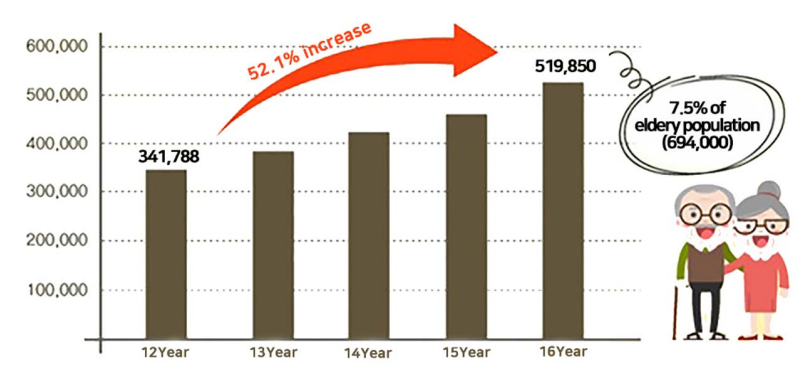

Fig. 2. Long-term care insurance pensioner (2016 Statistics Annual Report on Long-term Care Insurance for Senior Citizen).

Table 2. Recognition on long-term recovery (2016 Statistics annual report on long-term care insurance for senior citizens) (Unit: per person)

\begin{tabular}{lrrrrrr}
\hline \multicolumn{1}{c}{ Division } & 2012 & 2013 & 2014 & 2015 & 2016 & $\begin{array}{r}\text { Rate of increase } \\
\text { compare to 2012 }\end{array}$ \\
\hline Aging Population (65 and over) & $5,921,977$ & $6,192,762$ & $6,462,740$ & $6,719,244$ & $6,940,396$ & $17.2 \%$ \\
Applicant & 643,409 & 685,852 & 736,879 & 789,024 & 848,829 & $31.9 \%$ \\
Judging population (in-grade +out-grade) & 495,445 & 535,328 & 585,386 & 630,757 & 681,006 & $37.5 \%$ \\
Recognized population (Rate of recognition & 341,788 & 378,493 & 424,572 & 467,752 & 519,850 & $52.1 \%$ \\
compare to judging population) & $(69.0 \%)$ & $(70.7 \%)$ & $(72.5 \%)$ & $(74.2 \%)$ & $(76.3 \%)$ & $7.5 \%$ \\
Rate of recognition compare to aging population & $5.8 \%$ & $6.1 \%$ & $6.6 \%$ & $7.0 \%$ & $7 \%$ \\
\hline
\end{tabular}

Total medicaid population (excluding the dead). 
Table 3. Number of people on rate of recognition (2016 Statistics annual report on long-term care insurance for the aged) (Unit: per person)

\begin{tabular}{lrrrrrr}
\hline \multirow{2}{*}{ Division } & \multicolumn{9}{c}{2016} \\
\cline { 2 - 7 } & \multicolumn{1}{c}{ Total } & $1^{\text {st }}$ Grade & $2^{\text {nd }}$ Grade & $3^{\text {rd }}$ Grade & $4^{\text {th }}$ Grade & $5^{\text {th }}$ Grade \\
\hline Rate of Recognition & 519,850 & 40,917 & 74,334 & 185,800 & 188,888 & 29,911 \\
In general & 336,070 & 27,237 & 48,384 & 120,572 & 119,017 & 20,860 \\
Reduction & 94,630 & 6,768 & 13,889 & 35,093 & 34,125 & 4,755 \\
Medical cost & 6,266 & 454 & 849 & 2,266 & 2,339 & 358 \\
Supplemental security income & 82,884 & 6,458 & 11,212 & 27,869 & 33,407 & 3,938 \\
\hline
\end{tabular}

Table 4. Current state of specialists in long-term recovery institute for senior citizens

\begin{tabular}{lrrrrrrr}
\hline \multicolumn{1}{c}{ Division } & 2012 & 2013 & 2014 & 2015 & 2016 & $\begin{array}{c}\text { Market } \\
\text { Share }\end{array}$ & $\begin{array}{c}\text { Rate of increase } \\
\text { compare to the } \\
\text { year before }\end{array}$ \\
\hline Total & & & & & & & \\
Social workers & 253,115 & 274,243 & 292,889 & 324,946 & 344,242 & $5.9 \%$ \\
Doctors (including part-time employee) & 6,751 & 7,506 & 11,298 & 13,923 & 14,682 & $4.27 \%$ & $5.5 \%$ \\
Nurses & 1,142 & 1,233 & 1,324 & 1,415 & 1,683 & $0.49 \%$ & $18.9 \%$ \\
Nurses' aides & 2,735 & 2,627 & 2,683 & 2,719 & 2,675 & $0.78 \%$ & $\nabla 1.6 \%$ \\
Dental hygienists & 6,560 & 7,552 & 8,241 & 9,099 & 9,080 & $2.64 \%$ & $\nabla 0.2 \%$ \\
Physical therapists & 7 & 4 & 5 & 4 & 5 & $0.00 \%$ & $\nabla 25.0 \%$ \\
Care workers & 1,626 & 1,740 & 1,813 & 1,952 & 1,974 & $0.57 \%$ & $1.1 \%$ \\
Dietitian & 233,459 & 252,663 & 266,538 & 294,788 & 313,013 & $90.93 \%$ & $6.2 \%$ \\
\hline
\end{tabular}

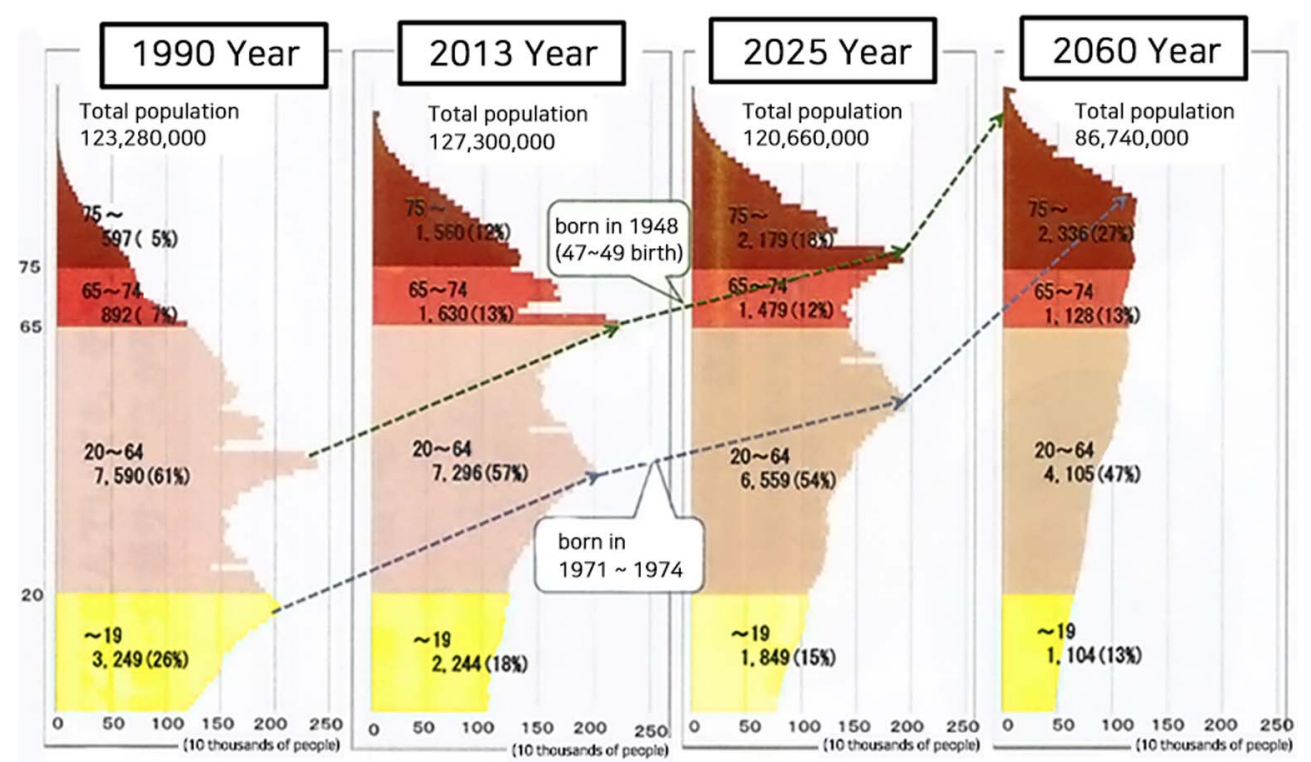

Fig. 3. The change of population pyramid in Japan.

세에 있지만, 장기요양기관은 2016년 기준 75,708개소, 입 소정원은 212,601명[8]으로 시설을 이용할 수 있는 인원이 제한적이고, 노인인구 대비 인정률도 $7.5 \%$ 로, 요양서비스 가 필요함에도 불구하고 많은 노인 환자들이 서비스 사각 지대에 놓여 있는 실정이다.

우리나라의 노인장기요양서비스는 서비스를 제공받는 장소에 따라 분류되고 있다. 시설입소는 주로 1,2 등급에 해당되며 장기간 입원 및 생활을 지원하는 서비스인 반면,
재가급여는 재가요양시설의 전문 인력이 가정에 방문하여 신체활동 및 가사활동을 지원하고 목욕, 간호 등을 제공하 는 것으로, 전문 인력에 의한 정기적인 모니터링과 처치가 필요한 경우 제공된다. 또한 주야간 보호센터나 1 3개월의 단기간 보호서비스도 재가급여에 포함된다. 재가급여의 방 문간호에 치과위생사에 의한 구강위생관리도 포함되어 있으 나, 2016년 현재 전국에 5명의 치과위생사[9](Table 4)만이 이 서비스 제공에 종사하고 있을 정도로 구강위생관리 서 
Jung-Min Kwag et al.

비스와 인력이 매우 미흡한 상황이다.

\section{2. 일본의 개호보험과 구강보건 서비스}

일본은 우리나라보다 30년 전인 1970년에 고령화 사회 에 진입한 이후, 1994년에 고령사회, 2005년에는 초고령 사회에 도달하였다. 1948년을 전후로 하여 태어난 세대가 모두 75 세가 되는 2025년에는 75 세 이상의 인구가 전 인 구의 $18 \%$ 이상을 차지할 것으로 예상되고 2060 년에는 65 세 이상이 전 인구의 $40 \%$ 이상을 차지할 것으로 예상되 는 등 고령화가 매우 심각하다(Fig. 3)[10].

인구 고령화 및 출산율의 감소에 더하여, 노인 요양을 가족이 부담하던 전통적인 경향이 가족규모의 축소, 자식 과의 동거세대 감소, 노인 부부와 노인 독거세대의 증가, 여성의 사회적 진출의 확대 등으로 인해 변화하면서 사회 적인 제도의 필요성이 대두되었다. 이러한 사회적 상황 속 에서 일본은 1990년대 중반기부터 고령사회에 즈음하여 기초지방자치단체인 시정촌의 역할 강화, 주민 공동체의 식에 기초한 노인 복지서비스의 시행, 장기 요양을 필요로 하는 노년층의 자립생활 지원 체제의 구축 및 노인의 삶 의 질 향상 등을 목표로 오랜 연구와 검토기간을 거쳐 2000년 4월 1일부터 개호보험 제도를 도입하고 시행하였 다[11]. 개호보험은 지역사회에 기초한 생활지원, 개호예 방과 재택 개호, 주거지원, 의료지원 등을 지역 포괄 지역 센터 중심으로 개호 대상 노인에게 제공하고 있다.

장애인이나 거동불편자를 포괄적으로 포함하여 치과 방 문이 어려운 취약 계층 및 시설 입소자에 제공하는 일본 의 구강보건서비스는 개호보험 서비스와 방문진료로 나눌 수 있다. 서비스는 대상의 등급에 따라 지원 필요 1,2 급과 개호 필요 1 5급으로 나누어 제공하며, 지원 필요 1,2 급은 예방 목적의 구강보건서비스를, 개호 필요 1 5급은 구강 관리 서비스 지도 및 구강위생관리, 틀니 관리, 섭식.연하 기능훈련 등을 제공한다(Table 5,6 ).

개호보험 서비스 이용자 또는 그 가족은 $10 \%$ 의 자기부 담금을 내며, 교통비는 실비를 지급한다. 일본의 치과 의 료기관 중 개호보험에 의한 재택 서비스를 실시하는 기관

Table 5. Long-term care insurance clause on dental health service (¥10 per unit)

\begin{tabular}{lr}
\hline $\begin{array}{l}\text { Instruction cost for domestic care implemented by } \\
\text { dentists }\end{array}$ & 500 unit \\
$\begin{array}{l}\text { Instruction cost for domestic care implemented by } \\
\text { dental hygienists }\end{array}$ & 350 unit \\
Include oral improvement in prevention benefit & 150 unit \\
Include oral improvement in care benefit & 150 unit \\
Include oral function maintenance system & 30 unit \\
Include oral function maintenance & 110 unit \\
Include oral maintenance & I. 28 unit \\
& II. 5 unit
\end{tabular}

Table 6. Medical insurance clauses on dental health service (¥10 per unit)

\begin{tabular}{|c|c|}
\hline $\begin{array}{l}\text { Medical fee for personal visit to the dental } \\
\text { hospital }\end{array}$ & 850 unit, 380 unit \\
\hline $\begin{array}{l}\text { Include respond to patients at home and } \\
\text { acute dentistry disease }\end{array}$ & $\begin{array}{l}170 \text { unit, } 50 \text { unit } \\
\text { (same building or not) }\end{array}$ \\
\hline Add of assistant for Dentist visit treatment & 110 unit, 45 unit \\
\hline Include regional medial solidarity system & 300 unit \\
\hline dental disease home treatment fee & 140 unit \\
\hline Include oral function maintenance & 50 unit \\
\hline Fees for dental disease management & 110 unit \\
\hline $\begin{array}{l}\text { Combined medical cost of dental treatment } \\
\text { of patient at home }\end{array}$ & 140 unit \\
\hline $\begin{array}{l}\text { Instruction cost for dental hygiene door-to- } \\
\text { door (complex) }\end{array}$ & 350 unit \\
\hline $\begin{array}{l}\text { Instruction cost for dental hygiene door-to- } \\
\text { door (single) }\end{array}$ & 100 unit \\
\hline $\begin{array}{l}\text { Instruction cost for solidarity of patients at } \\
\text { home }\end{array}$ & 900 unit \\
\hline $\begin{array}{l}\text { Conference fee for patients at home in } \\
\text { emergency }\end{array}$ & 200 unit \\
\hline
\end{tabular}

은 2,531개로 병원 총수의 $30 \%$ 정도이다[12].

또한 일본은 치과 방문진료가 가능하며 의료보험에 적 용된 수가에 방문진료의 특성을 반영한 가산이 이루어져 수가가 책정된다. 치과 방문진료의 본인 부담금은 통상적 인 의료보험 본인 부담금과 동일하며, 이 경우에도 교통비 는 실비로 징수한다. 일본에서는 노인이 구강질환을 포함 한 질병에 걸리면, 고도 급성기 병원에서 집중적인 1차 진 료를 받고, 예후에 따라 의료기관이나 자택 또는 요양시설 에서 방문진료 및 개호 서비스를 받는다. 이러한 결정은 재택 의료 연계거점과 지역 포괄 지원센터의 의료인과 케 어매니저 등에 의해 매우 체계적으로 이루어진다.

\section{3. 우리나라 노인장기요양보험 하의 치과촉탁의의 역할}

요양시설 입소 노인의 구강위생관리의 중요성은 단순한 구강건강의 유지 차원이 아닌 전신 건강 그리고 더 나아 가 노인의 삶의 질의 차원에서 고려해야 한다. 즉, 구강위 생관리의 미비로 인한 흡인성 폐렴의 증가, 치아 상실이나 치료 방치, 섭식.연하장애 등으로 인한 전신 영양상태의 저하, 구취로 인한 사회적인 기능의 저하 등 다양한 측면 에서 구강위생관리의 중요성이 부각되고 있다. 노인 환자 의 증가에 따라, 치과치료의 패러다임도 변화가 필요하다.

즉, 현재까지의 치과 치료가 단순히 충치나 치주질환과 같은 구강질환의 치료나 치아가 상실된 부분의 보철 수복 과 같은 구강 형태 회복 개념의 치료였다면, 고령화를 대 비한 치과치료는 예방과 구강기능의 재활의 범위까지의 확대된 치료 개념이 적용되어야 한다. 예를 들면, 고령 환 자들은 뇌혈관질환이나 인식장애, 또는 고령으로 인한 근 위축 등으로 인해 타액이나 음식의 오연이 빈번하게 발생 
되고, 만약 구강위생상태가 불량했을 때에는 포도상구균이 나 그람 음성 간균 등 병원성 세균의 구강인두 집락화가 증 가하여 흡인성 폐렴에 노출되는 것으로 보고되고 있다.

따라서, 구강위생관리와 연하운동 지도와 같은 예방과 재활치료에 있어 치과의사의 주도적인 역할이 요구된다. 고령화에 따른 또 다른 의료시스템의 변화는 환자가 직접 치과로 내원하여 치료를 받는 의사 중심의 치료에서 치과 로 내원하지 못하는 고령 환자를 찾아가는 수요자 중심의 치료로의 변화이다. 즉, 시설이나 가정에 거주하는 거동이 불편한 고령 환자들을 대상으로 한 구강건강관리에 대한 다양한 정책적 접근과 노력이 더욱 요구되며 이는 치과촉 탁의 제도의 안정화와 활성화를 통해 더욱 확대될 수 있 을 것이다.

촉탁의의 제도가 개정되기 전에는 재가급여 방문간호 중 치과위생사가 치과의사의 지시에 따라 거동이 불편한 재가 노인을 방문하여 구강위생관리를 제공할 수 있는 항
목이 유일한 구강보건서비스였다. 하지만, 치과촉탁의 제 도가 개정된 이후, 현재 권장되고 있는 시설에서의 치과촉 탁의의 활동은 더욱 구체화되고 다양화되었다. 치과촉탁 의에 대한 이해를 돕기 위해 치과촉탁의의 진료활동 및 내 용을 요약하면 다음 표와 같다(Table 7)[13].

\section{4. 입소 노인의 일상적인 구강건강관리를 위한 지침}

치과촉탁의의 활동과 관련하여 중요하면서도 가장 일상 적인 업무가 구강건강관리이다. 치과의사나 치과위생사가 상주하지 않는 현재의 요양시설의 특성상 일상적인 관리 는 요양보호사에 의해 이루어지며, 간호사나 사회복지사 가 이를 지도하고 관리할 수밖에 없다. 치과촉탁의가 있는 기관은 최종적으로 이에 대한 점검은 치과의사가 할 수 있 지만, 일상적으로 잘 관리하도록 교육하는 일은 매우 중요 하다.

이러한 이유로, 현재 치과촉탁의의 업무 중 하나로 일상적

Table 7. Dental examination in sanatorium

\begin{tabular}{ll}
\hline \multicolumn{1}{c}{ Treatments } & \multicolumn{1}{c}{ Contents } \\
\hline Oral health assessment & $\begin{array}{l}\text { Oral examination } \\
\text { Oral hygiene management }\end{array}$ \\
Oral hygiene management & $\begin{array}{l}\text { Oral malodor management } \\
\text { Dentures hygiene management and instruction } \\
\text { Oral soft tissue focus prevention and treatment }\end{array}$ \\
Oral topical pain management & Treatment on wound by dentures \\
& Treatment on side effect by medication \\
Improvement in oral function recovery & Xerostomia treatment \\
& Instruction on dysphagia \\
Optional treatment & Dentures adjustment \\
Prescriptions & Oral hygiene management by specialists \\
Hospital transfer & \\
\hline
\end{tabular}

Hospital transfer

Educational activities

Contents

Educational activities for residents

Educational activities for care workers

Oral hygiene training, dentures management, training on strengthening muscles around mouth

Daily oral hygiene management, Oral care product management, Managing methods on variety of symptoms caused by dysphagia

Table 8. Guideline on daily oral health care for new-coming elders

(1) Direct with systematic oral managing method to improve the quality of life of senior citizens in sanatorium.

(2) Provide oral management at least once a day to reduce the risk of pneumonia

(3) All residents must take oral examination once a year.

(4) Employ the systematic oral management to prevent the candida on dentures or oral and consult with the doctor to treat any infection.

(5) In case of resident under state where oral care cannot be done once a day, use gauze with chlorhexidine to wipe or apply $1 \%$ chlorhexidine gel once a day.

(6) Inspect the oral condition of resident with complaint of pain or nonverbal sign , then consult with doctor in case of any suspicious point. Nonverbal sign for oral pain includes change in behaviour, decrease in appetite and weight loss.

(7) Consult with doctor on residents with severe malodor.

(8) For residents with complaint of xerostomia, consult with doctor, maintain the humidity of residential environment and apply the moisturizer.

(9) Consult with doctor on residents with sudden increase of dental caries and use prescribed fluorine.

(10) Consult with doctor on oral side effects caused by medication 
인 구강건강관리를 할 수 있도록 교육하는 업무가 포함되어 있으며 이와 관련한 지침은 다음 표와 같다(Table 8)[14].

\section{5. 치과촉탁의 제도의 개선점 및 활성화를 위한 제언}

현재 치과촉탁의의 업무범위는 지나치게 제한적이고 수 가 또한 진찰료에 대한 비용만 책정되어 있고 행위료에 대 한 진료 수가가 이루어지지 않으므로 적정한 진료활동이 이루어지기 어려운 실정이다. 이처럼 현행 촉탁의 진료 수 가가 매우 낮게 책정되어 있기 때문에 치과촉탁의의 진료 활동은 '권장되는 활동'으로 표현하고 있다. 물론 현재 우 리나라의 장기 요양시설은 의료시설이 아니라 복지시설이 고, 전문적인 의료 행위는 의료기관에 이송하여 이루어지 는 것이 바람직하다. 하지만, 입소 노인은 대부분 거동이 상당히 제한적이고, 의료기관에 가기 위해서는 시설 종사 자나 가족이 함께 동반하여야 한다.

장기 노인 요양 등급 판정 노인은 본인도 건강보험료를 지불해 온 후, 현재는 가족이 건강보험료를 내고 있는 분 들이다. 그런데, 본인의 거동이 불편하여 의료기관에 접근 이 제한되어 적정한 진료를 받을 수 없는 상황에 처해있 는 것이다. 일본의 경우처럼 개호보험과 의료보험의 진료 를 받을 수 있도록 할 것인가는 여러 관점에서 논의가 필 요하겠지만, 의료 형평성의 관점에서 보아도 현행 촉탁의 의 활동 범위는 매우 인색하다 할 것이다. 이를 개선하기 위해서는 입소 노인의 진료 필요를 조사하고, 치과촉탁의 의 활동 범위를 최대한 확대하며, 유관 학회와 대한치과의 사협회의 모니터링 체계를 확립하고, 일반 환자와 차별되 는 진료 프로토콜을 개발하여 보급함으로써 현재의 제도 안에서 입소 노인의 구강건강을 증진시킬 수 있는 적극적 인 노력이 필요하다[15]. 즉, 치과촉탁의의 활성화를 위해 서는 먼저, 요양시설이나 재가 노인에 대한 방문 치료가 이루어질 수 있도록 의료정책의 유연성과 의료시스템의 확보가 요구된다.

환자 및 시설 종사자들에 대한 적극적인 홍보 및 인식 의 전환도 매우 중요하다. 현재는 월 2회에 제한되어 촉탁 의를 방문을 요청할 수 있으므로 장기 요양시설의 입장에 서는 기존의 촉탁 의사나 한의사를 지정하는 경우가 대부 분이다. 하지만, 구강위생관리의 중요성이 전신 건강에 미 치는 영향이나 또는 구강기능 재활에 대한 새로운 진료 모 형이 노인들의 삶의 질에 미치는 효과에 대해 교육하고 인 식시킴으로써 치과촉탁의 제도의 점차적인 활성화가 이루 어질 수 있을 것이다.

현재 전국에서 치과의사로서 촉탁의 활동을 하도록 지 정 받은 사람은 15 명에 불과한 실정이다. 노인장기요양 보험 하에서 치과촉탁의 제도가 안정적으로 자리잡기 위 해서는 무엇보다도 치과의사들 스스로 치과촉탁의에 대 한 이해가 우선되어야 하고, 의료업종 간 팀 어프로치가
요구되는 고령 환자의 치료에 있어 주도적인 역할이 요 구된다.

\section{결 론}

요양시설 입소 노인에게 적절한 구강건강관리와 구강기 능의 회복은 일차적으로 영양 공급에 따른 전신적인 건강 과 정서적 만족감을 회복해줄 수 있는 것은 물론, 인생의 마지막을 존엄하게 지낼 수 있게 해준다는 측면에서 중요 한 의미가 있다.

또한 전신질환과 구강건강수준의 연관성을 고려할 때, 신체적으로 취약한 노인들의 건강관리 및 만성질환 관리 에 구강건강관리가 포함되어야 한다. 이런 측면에서 치과 의사와 의사(한의사), 관련 업종간의 팀 어프로치를 통해 포괄적으로 건강을 관리하도록 하는 제도의 내실화는 매 우 중요하다 하겠다.

현행 치과촉탁의 제도는 진료범위가 매우 제한적이고, 치과촉탁의 선정이 의무조항이 아닌 선택사항으로 되어 있어, 전신질환 관리가 상대적으로 중요한 노인요양시설 에서의 활동이 매우 제한되어 있다. 이를 개선하기 위해서는 진료범위를 현행 제도가 허용하는 한 많이 늘리고 치과촉탁 의 지정을 의무로 하는 방안을 검토하여야 할 것이다.

노인 인구의 증가와 더불어 치과 의료의 패러다임도 변 화하고 있다. 고가의 장비와 시설이 있는 병원에 내원하지 않더라도 적정한 치과진료를 받을 수 있는 방문 치과진료 에 대한 심도 있는 고민이 필요한 때이다. 이를 위해 학계, 대한치과의사협회, 정부가 공동으로 진료 수요 조사와 새 로운 프로토콜의 보급, 모니터링 체계의 구축을 위한 공동 의 노력이 요구된다.

고령화를 대비한 다양한 의료정책을 개발하고 변화에 대응하기 위해, 치과의사의 역량 강화가 우선되어야 한다. 더불어 구강에 한정하지 않고 환자의 '삶의 질'을 유지하 고 증진시키는 것을 최종적인 목적으로 하는 치과 의료인 의 새로운 인식 변화가 요구된다.

\section{Acknowledgements}

This study was supported by a research fund from Chosun University, 2016.

\section{Conflict of Interest}

The authors declare that they have no competing interests. 


\section{ORCID}

\author{
Jung-Min Kwag 0000-0001-8607-6580 \\ Inn-Im Park 0000-0001-8410-5798 \\ Mee-Kyoung Son 0000-0001-9225-1744
}

\section{References}

1. 2009 Statistics of Senior Citizens, Statistics office, 2009.

2. Jeong JW. The Aging Era and Long-term Care Insurance Scheme. Dae Yong Publishing, 2015. p. 15.

3. Enforcement Regulation on Welfare of the Aged Act Article 22 (Revised Aug. 31 $1^{\text {st }}$. 2016).

4. Korean Dental Association. Provided by Culture and Welfare Commission, 2017.

5. Life Table, Statistics office p.4.

6. Reference on Announcement of WHO 2015.

7. Jeong KH. Survey on the Elderly Life Condition 2014. Ministry of Health and Welfare, Korea Institute for Health and Social Affairs 2015.

8. Current State of Welfare Facilities for Senior Citizens, Ministry of Health and Welfare 2017.

9. Sung SC. 2016 Statistic Annual Report on Long-term
Care Insurance for Senior Citizen. National Health Insurance Corporation Big Data Operations Center/ Statistical Department 2017.

10. The First Korea and Japan Social Policy Ordinary Forum: The shock and respond to low birth rate and aging population. Korea Institute for Health and Social Affairs, National Social Security, Japan's Population Research Institute.

11. Jeong JU. Aging Era and Long-term Care Insurance Scheme for Senior Citizens. Dae Yong Publishing, 2015. p.120.

12. Dental Institute for Dental Policy: Survey on Dental Care Service Implemented in Japan's Long-term Recovery Institute for Senior Citizens. Korean Women's Dental Association, 2016. p.15.

13. Korean Academy of Dental Science for Senior Citizens: Gerodontics. Ji-seong Pulisher, 2016. p.489-490.

14. De Visschere LM, van der Putten GJ, Vanobbergen JN, Schols JM, de Baat C; Dutch Association of Nursing Home Physicians. An oral health care guideline for institutionalised older people. Gerodontology 2011;28:307310. doi: 10.1111/j.1741-2358.2010.00406.x.

15. Office of Population Policy-Office of Senior Citizen's Policy Management Office: Division of Health Care Insurance: Research on Introducing the Entrustment of Dental Service in Nursing Care Facilities. Ministry of Health and Welfare, 2014. p.133. 